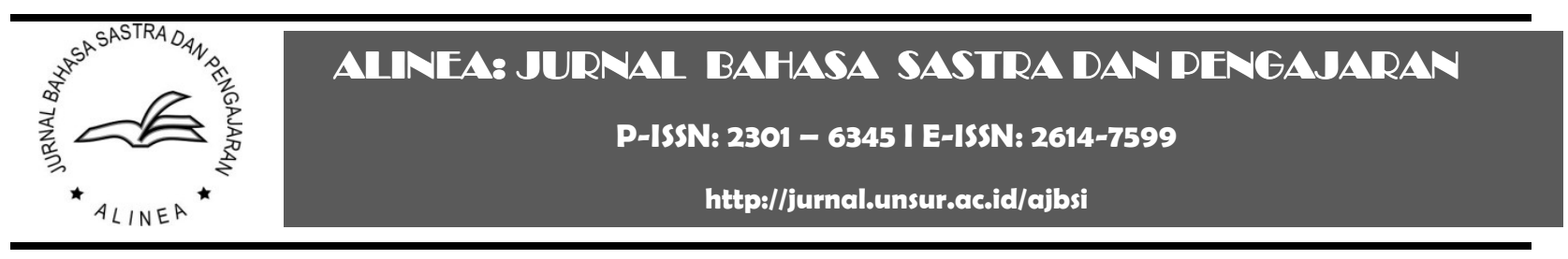

\title{
INTERTEKSTUAL DEKONSTRUKTIF NOVEL LAMBUNG MANGKURAT ATAS HIKAYAT BANJAR DAN TUTUR CANDI
}

\author{
Dewi Alfianti \& Ahsani Taqwiem \\ Universitas Lambung Mangkurat, Banjarmasin
}

Riwayat artikel:

Dikirim: 6 Desember 2019

Direvisi: 6 Januari 2020

Diterima: 8 Februari 2020

Diterbitkan: 30 April 2020

Katakunci:

dekonstruktif

intertekstual

Lambung Mangkurat

Alamat surat

dewialfianti@ulm.ac.id

\begin{abstract}
Abstrak:
Tulisan ini bertujuan untuk mengetahui interteksualitas dan dekonstruksi novel "Lambung Mangkurat", dan dua hipogramnya, "Hikayat Banjar" dan "Tutur Candi”. Penelitian dilakukan menggunakan analisis intertekstual model Julia Kristeva dan dekonstruksi Jaqcues Derrida. Hasil analisis menunjukkan ada sejumlah perbedaan pada bagian jalan cerita dan penokohan. Pada novel tidak ada hal-hal gaib, berbeda dengan dalam kedua hipogram. Tokoh Lambung Mangkurat dan Junjung Buih dalam novel diberi atribut serba sempurna sementara di dalam novel muncul dengan segala kekurangan dan kelemahan sebagaiman manusia biasa yang memiliki ambisi, kelemahan, dan ketakutana yang di dalam dua hipogram tidak ada. Di dalam novel Lambung Mangkurat diceritakan berhasil menjadi Raja Nagara Dipa berkat bantuan Gajah Mada, juga dicerita terjadi pemberontakan Kerajaan Kuripan yang di dua hipogram tidak. Perbedaan ini terjadi sebagai upaya pengarang untuk menafsirkan ulang dan memaknai kembali cerita Lambung Mangkurat dalam perspektif yang lebih sesuai dengan zamannya.
\end{abstract}

\begin{abstract}
:
This paper aims to find out the intertexuality and deconstruction of the novel "Lambung Mangkurat", and two hypograms, "Hikayat Banjar" and "Tutur Candi". The study was conducted using intertextual analysis of Julia Kristeva's model and Jaqcues Derrida's deconstruction. The analysis shows that there are a number of differences in the part of the storyline and characterizations. In the novel there are no supernatural things, different from the two hipograms. The gastric characters of Mangkurat and Junjung Buih in the novel are given allround attributes while in the novel appear with all the shortcomings and weaknesses as an ordinary human being who has ambition, weakness, and fear which in his two hypotheses do not exist. In the novel Lambung Mangkurat is said to have succeeded in becoming Raja Nagara Dipa with the help of Gajah Mada, there was also a story of a revolt of the Kingdom of Kuripan which in two hypograms did not. This difference occurs as the author's attempt to reinterpret and reinterpret the story of Lambung Mangkurat in a perspective that is more appropriate to the era.
\end{abstract}

\section{PENDAHULUAN}

Dalam kehidupan sehari-hari, manusia sering melakukan tindak asosiatif dengan menghubungkan satu hal dengan hal lainnya, termasuk menghubungkan satu teks dengan teks lainnya. Asosiasi berkaitan dengan pengetahuan yang dimiliki sebelumnya dan dihubungkan dengan apa yang sedang diidentifikasi saat ini. Terkait dengan teks, kemampuan asosiatif inilah yang memungkinkan seorang penulis dan pembaca teks menghubungkan apa yang sedang dia baca dengan sesuatu yang mungkin pernah dibaca, didengar, atau dilihatnya di suatu waktu di masa lampau. Pada akhirnya, pembahasan sederhana tentang asosiasi ini kemudian bisa berkembang menjadi sesuatu yang lebih kompleks karena ketika membahas satu teks (lisan atau tulisan) kita mungkin akan membahas jalinan-jalinan asosiatif antara teks itu dengan teks-teks lainnya. 
Saat mendengar cerita rakyat dan atau mitos "Malin Kundang" di Sumatera Barat, "Sitanggang" di Malaka, dan "Raden Pengantin" di Kalimantan Selatan, misalnya, besar kemungkinan pembaca akan menyimpulkan keterkaitan antara ketiganya karena ada kemiripan struktur dan isi ceritanya yaitu tentang anak durhaka yang dikutuk menjadi batu. Asosiasi tentu tidak salah, karena cerita itu secara lisan lahir dan dituturkan di satu tempat lalu menyebar dan mengalami penyesuaian dengan kebudayaan di wilayah sebaran barunya hingga melahirkan cerita-cerita lain yang sangat mirip.

Contoh keterkaitan ketiga teks (lisan) di atas yang secara asosiatif dimaknai sebagai cerita-cerita yang sangat mirip itu dapat dijelaskan dengan intertekstualitas. Dalam pandangan interteksual, dunia teks adalah dunia ketika teks-teks (lisan atau tertulis) saling terhubung, bertalian, pengaruh-memengaruhi satu dengan yang lainnya. Tidak ada teks yang hadir dari ruang hampa tanpa pengaruh apapun dari teks-teks sebelumnya. Terhadap teks pendahulunya (hipogram), teks yang hadir kemudian senantiasa memberikan geliat baru, pemaknaan baru, dan bentuk baru. Hal ini terjadi karena teks lahir dalam kurun yang lebih kemudian daripada hipogram, berada dalam lintasan pengalaman dunia yang lebih kompleks dari hipogramnya itu. teks selanjutnya itu bisa menjadi penguat, penyanggah, atau bahkan perusak hipogramnya. Dalam posisi ini, teks baru itu mendekonstruksi hipogramnya.

Kaitan antara intertekstualitas dan dekonstruksi menjadi tak terelakkan karena peristiwa pengaruh mempengaruhi antara hipogram dan teks selanjutnya selalu terjadi secara dekonstruktif. Tidak ada teks selanjutnya yang sama persis dengan hipogramnya. Teks yang hadir belakangan ini akan memainkan peranannya baik sebagai penguat, opisisi, atau bahkan perusak hipogramnya. OLeh karena itu, menarik untuk melihat bagaimana sebuah teks mendekonstruksi terhadap hipogramnya.
Dalam khazanah kesusastraan Melayu, sejumlah manuskrip mengenai kesultanan Banjar di Kalimantan Tenggara (hari ini meliputi Kalimantan Selatan, sebagian Kalimantan Tengah dan Timur) telah ditulis pada abad ke19, di antaranya adalah Hikayat Banjar dan Tutur Candi yang menceritakan asal mula kerajaan Banjar di wilayah Kalimantan Tenggara dan perkembangannya. Keduanya diduga sebagai hipogram dari novel Lambung Mangkurat yang ditulis oleh Randu Alamsyah beberapa ratus tahun setelahnya. Novel yang terbit pada tahun 2018 ini diterbitkan oleh Laksana, grup Diva Press dan didistribusikan secara nasional.

Novel Lambung Mangkurat memiliki dimensi yang sama dengan novel-novel lain yang berbicara tentang sejarah (atau mitos) raja dan penguasa pada masa kerajaan HinduBudha, seperti novel Gajah Mada karya Langit Kresna Hadi, Senopati Pamungkas karya Arswendo Atmowiloto, atau Arok Dedes karya Pramoedya Ananta Toer. Ia novel yang berangkat dari cerita perpaduan mitos dan sejarah Nusantara jauh sebelum negara Indonesia dibentuk. Cerita-cerita yang telah lekat selama berabad-abad dengan pemahaman masyarakat tentang bagaimana nenek moyangnya di masa lalu, kejayaan dan keruntuhan mereka. Cerita yang membentuk identitas bangsa kita hari ini.

Bagi masyarakat Banjar sendiri, cerita Hikayat Banjar adalah cerita mistis dan sakral mengenai asal usul mereka. Eksistensi mereka berawal dari cerita ini, dan dari cerita inilah identitas urang Banjar dibentuk. Karena dianggap berkaitan dengan hikayat yang menceritakan asal muasal kerajaan Banjar, novel Lambung Mangkurat juga pernah dibedah di Universitas Lambung Mangkurat, Banjarmasin, oleh sejarawan Helius Sjamsuddin dalam konteks komparasi kesejarahan dengan buku-buku hipogramnya.

Tulisan berikut ini akan membicarakan intertekstualitas novel Lambung Mangkurat terhadap Hikayat Banjar dan Tutur Candi serta akan membahas bagaimana novel 
Lambung Mangkurat mendekonstruksi dua hipogramnya, Hikayat Banjar dan Tutur Candi.

Kajian intertekstualitas dan dekonstruksi merupakan kajian yang lazim dalam postruktural sebagai sebuah respon pada fokus pembacaan teks yang hanya melihat struktr internal teks sastra. Kedua pendekatan ini melihat teks pada relevansinya dengan teks lain baik dalam hubungan pengaruh-memengaruhi teks tersebut dengan teks lainnya maupun usaha teks untuk membangun ulang pemahaman berbeda terhadap teks lain.

Secara terpisah, dua kajian ini telah menjadi pendekatan yang cukup mapan dan banyak digunakan dalam memahami dan menguraikan sebuah teks sastra. Untuk kajian intertekstual misalnya, ada sejumlah penelitian teks sastra yang menggunakan pendekatan ini, misalnya artikel ilmiah berjudul Kajian Intertekstual Sang Pemimpi Karya Andrea Hirata dan Mengejar-ngejar Mimpi Karya Dedi Padiku (Yaumi), atau dalam bentuk tesis, karya Asep Supriadi yang berjudul Transformasi Nilai-Nilai Ajaran Islam dalam AyatAyat Cinta Karya Habiburrahman el Shirazy, Kajian Interteks (Supriadi). Kedua tulisan itu menggunakan interteksual sebegai pendekatan, mereka membandingkan dua teks untuk melihat bagaimana pengaruh masing-masing teks terhadap teks lainnya.

Sementara itu, kajian tentang dekonstruksi contohnya dapat dilihat dari beberapa tulisan artikel jurnal berikut, Analisis Dekonstruksi Tokoh Tekeshi dan Mitsusaburo dalam Novel Silent Cry Karya Kenzaburo Oe Perspektif Jaqcues Derrida (Ghofur); Dekonstuksi Patriarki Khaled Hosseini dalam Novel $A$ Thousand Splendid Sun (Suciati), dan Dekonstruksi Budaya Kekuasan dalam Novel Ca Bau Kan Karya Remy Silado (Asmarani). Masalah yang dibahas dalam tulisan-tulisan ini adalah bagaimana bagian novel, entah itu tokoh, latar, atau cerita, mendekonstruksi tatanan yang sudah lazim.
Kedua kajian postruktural ini dibahas secara terpisah, padahal keduanya memiliki relevansi. Keduanya sama-sama membicarakan lebih dari satu teks dan hubungan antara keduanya. Salah satu artikel jurnal yang mengaitkan antara dua kajian ini adalah artikel berjudul Dekonstruksi Struktur Penceritaan dalam Novel Arok-Dedes: Kajian Intertekstual (Purwanti). Meski sama-sama membahas kaitan antarteks dengan pendekatan interteks dekonstruksi, tulisan yang berjudul Interteks Dekonstruktif Novel Lambung Mangkurat atas Hikayat Banjar dan Tutur Candi ini memiliki kebaruan terutama pada obyek tulisan, dan pada dimensi teks yang merupakan perpaduan teks sastra kontempirer dan klasik.

\section{Intertekstual dan Dekonstruksi}

Intertekstual adalah pandangan yang melihat teks tidak sebagai teks an sich, tetapi teks ditarik dalam hubungannya dengan teksteks lainnya. Teks dibuat dari apa yang disebut teksualitas budaya atau sosial. Dalam hal ini, teks bukan ihwal individual atau objek terisolasi, tapi lebih dari itu, ia adalah perpaduan tekstualitas budaya. Teks individual dan teks budaya berasal dari material yang sama dan tidak bisa dipisahkan satu sama lain. Sebuah teks tak bisa dilepaskan dari teks-teks lainnya -teks-teks lain ini termasuk material yang sifatnya abstrak: ide, gagasan, ideologi, kebudayaan, dan lainnya. Teks tak bisa dipisahkan dari lingkungan kebudayaan atau tekstualitas sosial di mana mereka dibentuk. Semua teks mengandung struktur ideologis, dan ekspresi perjuangan sosial, (Allen).

Pemahaman tentang keterkaitan antarteks inilah yang menjadi dasar pendekatan intertekstualitas dalam karya sastra. Pendekatan intertekstual menganggap bahwa suatu teks tidak berdiri sendiri tapi terkait dan relevan dengan teks-teks lain. Ada dua alasan yang melatarbelakanginya, (1) pengarang sebagai pembuat teks adalah pembaca teks-teks lain. Dalam membaca teks ia menggunakan rujukan, dan atau mengutip, (2) teks tersedia melalui proses pencarian materi yang hendak ditulis, (Rokhmansyah). Menurut Julia 
Kristeva, penggagas intertekstual, pengarang tidak orisinal dan tidak menciptakan hal orisinal apapun dari pemikirannya kecuali memadukan teks-teks yang sudah ada, (Elmo Raj).

Dalam hubungan antarteks ini ada tiga tipe intertekstual (Jacobmeyer; Fitzsimmons) 2013) yaitu (1) obligatory intertextuality: intertekstual yang terjadi ketika pengarang sengaja melibatkan perbandingan atau asosiasi antara dua teks atau lebih di mana ketika tidak memahami asosiasi ini atau ketika tidak mampu menemukan hubungan, pemahaman pembaca akan teks itu tidak memadai; (2) optional intertextuality: hubungan yang ada tidak terlalu berpengaruh terhadap masingmasing teks, terjadi tapi tidak esensial. Meskipun ada, hubungan itu cenderung sedikit saja memengaruhi teks. Kebutuhan pengarang menggunakan interteks ini sekadar menghargai pengarang 'aslinya' atau menghargai siapapun yang membaca teks sebelumnya. Pembacaan terhadap hipogram (teks sebelumnya) tidak diperlukan dalam memaknai teks selanjutnya; (3) accidental intertextuality: ketika pembaca kadang menghubungkan sebuah teks dnegan teks lain, praktik budaya, pengalaman pribadi, tanpa memengaruhi teks aslinya. Interteks ini sangat bergantung pada pengetahuan pembaca atas teks sebelumnya.

Dalam intertekstual dikenal istilah hipogram/prior text yaitu teks-teks (kesastraan) yang dijadikan dasar penulisan bagi teks yang kemudian. Wujud hipogram mungkin berupa penerusan konvensi, sesuatu yang telah bereksistensi, penyimpangan dan pemberontakan konvensi, pemutarbalikan esensi dan amanat dari teks-teks sebelumnya, (Nurgiyantoro).

Dalam konteks teks baru yang menjadi respon atas hipogramnya inilah, intertekstual kemudian dikaitkan dengan konsep dekonstruksi, karena sebagai bentuk respon, teks selanjutnya cenderung membongkar makna yang sudah mapan dipahami atas hipogramnya. Pengarang teks selanjutnya, sadar atau tidak, menafsirkan kembali hipogramnya lalu memberikan tafsiran baru yang mungkin berbeda dari penafsiran yang sudah lumrah mengenai hipogram itu. di sinilah proses menghancurkan dan menata kembali itu berlangsung.

Dekonstruksi pada hakikatnya merupakan suatu cara membaca sebuah teks yang menumbangkan anggapan (walaupun itu hanya secara implisit) bahwa sebuah teks memiliki landasan, dalam sistem bahasa yang berlaku, untuk menegaskan struktur, keutuhan, dan makna yang telah menentu, (Nurgiyantoro). Dengan demikian stabilitas teks dengan maknanya yang pasti dan mapan tak dapat dipertahankan, apalagi sampai ratusan tahun. Perlu pembacaan ulang dari masa ke masa untuk bisa menemukan titiktitik penyesuaiannya, bahkan jika diperlukan membongkar teks (dalam rangka merapikannya kembali) untuk mendapatkan pemaknaan yang lebih sesuai dengan masanya.

Dekonstruksi adalah pengingat kita pada hubungan etimologi antara krisis dan kritik, Ini adalah perwujudan fakta bahwa bagian 'radikal' dari penafsiran harus selalu menang melawan batas dari hal-hal yang tampak tidak jelas/ samar. Dekonstruksi bekerja di batas yang memusingkan, mencurigai segala yang telah diterima dengan mapan oleh bahasa, pengalaman, dan kemungkinan-kemungkinan normal dari komunikasi manusia. Dekonstruksi adalah antitesis dari yang mungkin berterima dalam konsep dan nilai tradisional. Dekonstruksi sebagai bagian dari posstruktural menolak ide struktural bahwa makna atau rasa secara objektif ada di dalam teks, (Norris).

\section{METODE}

Pendekatan yang dipakai dalam penelitian ini adalah pendekatan kualitatif. Dengan pendekatan ini, analisis data dilakukan dengan menggunakan konstruksi penelitian kualitatif. Pendekatan ini diarahkan pada latar dan individu secara holistik (utuh). Pengumpulan data dilakukan dengan memilah data yang sesuai dengan penelitian. Data yang sesuai 
dengan kepentingan penelitian akan disisihkan dari yang tidak relevan. Data yang sudah dipilah kemudian dideskripsikan, dan ditafsirkan.

Sumber data pada penelitian adalah tiga teks, (1) novel Lambung Mangkurat yang ditulis oleh Randu Alamsyah, diterbitkan pertama kali tahun 2016 oleh Laksana, (2) Hikayat Banjar karya J.J. Rass, diterbitkan tahun 1990 ke dalam bahasa Melayu Malaysia, ditulis oleh Siti Hawa Salleh, diterbitkan Percetakan dewan Bahasa dan Sastra Malaysia, (3) Tutur Candi, ditulis kembali oleh Muhammad Idwar Saleh tahun 1986. Diterbitkan oleh Balai Pustaka bekerjasama dengan Perpustakaan Nasional. Data dalam penelitian ini adalah kata dan kalimat dari ketiga teks di atas yang berhubungan relevan dengan kajian interteksual dekonstruktif.

\section{HASIL DAN PEMBAHASAN}

Pendokumentasian narasi tentang asal mula dan perkembangan Kerajaan Banjar di Kalimantan Tenggara yang awalnya berupa tuturan lisan telah dimulai oleh cendikiawan keraton Banjar. Disebutkan dalam buku Hikayat Banjar, sejak awal abad ke-19 cerita ini telah pula menarik perhatian banyak sarjana Eropa. Periwayatan dan sumber yang berbeda-beda menyebabkan cerita ini memiliki dua arus besar cerita dengan judul masingmasing: Resensi 1 dan Resensi 2.

Resensi 1 dianggap lebih 'akademis' karena berasal dari periwayatan terus menerus dari manuskrip ke manuskrip. Resensi 1 lebih bersifat istana-sentris karena dibuat untuk melegitimasi kekuasaan kerajaan Banjar dan kali pertama pendokumentasiannya ke dalam manuskrip berbahasa Banjar huruf Arab Melayu dilakukan oleh kalangan keraton Banjar. Dari periwayatan tulis kalangan istana yang menggunakan bahasa Banjar dan huruf Arab Melayu inilah, ahli filologi Belanda dan Inggris di masa Stamford menyalinnya ke dalam bahasa Inggris/Belanda dengan huruf latin.
Sementara itu, Resensi 2 berangkat dari periwayatan lisan ke lisan dengan cerita yang berkembang di kalangan rakyat biasa. Resensi 2 bahkan diidentifikasi sebagai tuturan cerita yang disampaikan pada pertunjukan wayang Abdul Muluk. Oleh para ahli filologi, Resensi 2 cenderung diabaikan karena sifatnya yang bertele-tele dan terlalu fantastis, tetapi seorang pribumi, guru sekolah Gubermen bernama Mohammad Seman, menyalinnya dari lisan ke tulisan dengan huruf Arab Melayu pada tahun 1937. Manuskrip inilah yang disebut Resensi 2 dan di kemudian hari lebih dikenal sebagai Tutur Candi.

\section{Hikayat Banjar}

Hikayat Banjar ditulis oleh Johannes Jacobus Rass (J.J. Rass), seorang filolog berkebangsaan Belanda. Buku ini ditulis dalam Bahasa Inggris dengan judul Hikajat Bandjar, A Study in Malay Historiography dan diterbitkan tahun 1968 di Belanda. Tahun 1990, Hikajat Bandjar diterjemahkan ke dalam Bahasa Melayu Malaysia dengan judul Hikayat Banjar dengan penerjemah Siti Hawa Salleh.

Hikayat Banjar berasal dari berbagai manuskrip di era kolonial Belanda yang secara khusus membicarakan tentang asal mula dan perkembangan kerajaan Banjar dan Kotawaringin. Manuskrip itu ditulis dalam Bahasa Melayu Banjar. Beberapa manuskrip mencampur bahasa Melayu Banjar dengan bahasa Jawa. Sebagian ditulis dengan aksara latin, sebagiannya dengan aksara Arab Melayu. Manuskrip-manuskrip itu lantas dibandingkan dan dikombinasikan untuk bisa saling melengkapi naskah yang ditulis oleh J.J. Rass ini.

Hikayat Banjar dibagi ke dalam 12 episode yang secara berturut-turut menceritakan mengenai asal mula kerajaan Banjar, yaitu Negara Dipa (Keraton I), dilanjutkan masa Negara Daha (Keraton II), dilanjutkan masa kerajaan Bandarmasih (Keraton III) sampai masa kerajaan Martapura (Keraton IV). Masa yang tercatat memiliki bukti-bukti sejarah dimulai sejak masa kerajaan 
Bandarmasih dengan raja pertamanya Sultan Surianysah, sedangkan sebelum masa ini, bukti-bukti sejarah hanya sebatas lokasi reruntuhan Candi Agung (istana kerajaan awal Negara Dipa), selebihnya masih berada di wilayah mitos dan perdebatan (Rass).

Secara singkat dapat diceritakan: bagian Keraton I meliputi episode 1-7. Berisi cerita awal mula pelayaran Ampu Jatmika ke Banua Hujung Tanah, sesampainya di sana ia bermukim lalu membangun negeri baru bernama Nagara-Dipa (Tanah Bercahaya). Ampu Jatmika kemudian memerintahkan kepada bawahannya untuk membuat patung sebagai pengganti raja dan ratu karena ia sendiri bukan berasal dari kasta raja sehingga merasa tak berhak menjadi raja. Saat ia sakit ia menyampaikan hal yang sama pada dua putranya, Ampu Mandastana dan Lambung Mangkurat agar tidak bercita-cita menjadi raja dan menyuruh mereka bertapa untuk mencari raja baru. Lambung Mangkurat berhasil mendapatkan Putri Junjung Buih melalui pertapaannya lalau mengangkat sang putri menjadi raja di kerajaan Nagara Dipa. Kelak, Lambung Mangkurat membunuh dua keponakannya, Bangbang Sukmaraga dan Bangbang Patmaraga karena ia melihat ada indikasi Sang Raja Putri mulai jatuh cinta pada mereka.

Agar Raja Putri Junjung Buih segera mendapatkan suami, Lambung Mangkurat lantas mendatangi raja Majapahit untuk meminta putra yang didapatkannya dari pertapaan menjadi suami Raja Putri Junjung Buih. Setelah tiga hari pemujaan, muncullah Raden Putera yang bergelar Suryanata. Di akhir episode 7, Raja Putri Junjung Buih menikah dengan Raden Suryanata sehingga tertasbihkanlah pasangan penguasa Nagara Dipa, Maharaja Suryanata dan Ratu Junjung Buih.

Episode 8-9 merupakan bagian Keraton II, yang banyak menceritakan tentang cucu dari Maharaja Suryanata dan Ratu Junjung Buih, yaitu Raden Sekar Sungsang yang hilang saat masih kecil, mengembara ke Jawa saat remaja lalu kembali ke Kalimantan dan mengambil tahtanya dari Ibunya. Raden Sekar Sungsang ini kemudian bergelar Maharaja Sari Kaburungan. Ia memindahkan pusat keraton dari Nagara Dipa ke Nagara Daha. Di masa ini Lambung Mangkurat meninggal digantikan Aria Taranggana.

Episode 10-11 adalah permulaan Keraton III yaitu Kerajaan Bandarmasih. Episode ini menceritakan Raden Samudra, cicit Maharaja Sari Kaburungan. Raden Samudra ditunjuk sebagai pewaris tahta oleh kakeknya dan itu membuat pamannya, Pangeran Tumenggung murka dan berniat membunuhnya. Raden Samudra melarikan diri sampai di daerah Muara Kuin, Bandarmasih. Patih Masih, penguasa setempat yang mengetahui silsilah dan keutamaannya, mengangkat Raden Samudra menjadi raja di wilayah Bandarmasih. Pangeran Tumanggung menyerang Raden Samudra tetapi berhasil dikalahkan. Raden Samudra meminta bantuan kesultanan Demak. Bantuan diberikan jika Raden Samudra dan seluruh rakyatnya bersedia masuk Islam. Syarat itu disetujui, dan Raden Samudra berganti gelar menjadi Sultan Suryanullah atau Sultan Suriansyah.

Episode 12 yang merupakan episode terakhir dalam Hikayat Banjar ini menceritakan tentang anak keturunan Sultan Suriansyah, yaitu Sultan Rahmatullah, kemudian anaknya, Sultan Mustainullah (Marhum Panambahan). Akibat dibom Belanda, Marhum Panambahan memindahkan kerajaan ke Martapura sehingga mengawali fase Keraton IV di Martapura.

\section{Tutur Candi}

Cerita Tutur Candi sejalan dengan Hikayat Banjar, tetapi hanya terdiri dari 11 episode saja (Saleh). Tutur Candi tidak membahas fase Keraton IV. Bagian tiap-tiap episode Tutur Candi serupa saja dengan Hikayat Banjar hanya saja dengan versi yang lebih panjang dan berbelit-belit, banyak disisipi hal-hal fantastis, tetapi pada bagianbagian tertentu, melengkapi kekurangan 
informasi yang ada pada Hikayat Banjar. Beberapa pengembangan atau informasi penting yang terdapat dalam Tutur Candi sebenarnya membantu pembaca untuk memahami keseluruhan narasi kerajaan Banjar -terutama di bagian-bagian awal.

Misalnya saja, pada episode 1 di Hikayat Banjar tidak diceritakan mengenai latar belakang keluarga Ampu Jatmika, tetapi Tutur Candi mengulasnya panjang lebar, termasuk memasukkan tokoh-tokoh popular dalam Islam seperti Sultan Iskandar dan Nabi (Hadir) Khidir sebagai bagian silsilah keluarga Ampu Jatmika. Hal ini menunjukkan bahwa pengaruh Islam sudah terasa di awal pembentukan kerajaan Banjar jauh sebelum kesepakatan dengan Demak untuk mengislamisasi kerajaan Banjar dilakukan. Keterangan tambahan juga didapatkan dalam Tutur Candi di episode ke-2, yaitu munculnya nama Kuripan sebagai penguasa lokal di wilayah Banua Hujung tanah sebelum Ampu Jatmika datang. Selain penambahan-penambahan, dalam Tutur Candi juga ditemukan perbedaan dalam penjelasan silsilah anak keturunan Maharaja Suryanata dan Ratu Junjung Buih.

J.J. Rass (1993:75) menjelaskan perbedaan mendasar dalam Hikayat Banjar dan Tutur Candi terletak pada (1) gaya bercerita, Hikayat Banjar lebih ringkas sedangkan Tutur Candi bertele-tele dan mengandung lebih banyak hal-hal ajaib di luar akal (Rass menyebutnya versi yang diromantiskan); (2) pada dasarnya Hikayat Banjar Resensi 1 adalah teks keraton yang dibuat di lingkungan keraton untuk melegitimasi kekuasaan pihak keraton, sedangkan Tutur Candi adalah teks wayang yang beredar secara luas di masyarakat melalui pertunjukan teater rakyat Abdul Muluk. Dengan titik tekannya masingmasing, Hikayat Banjar lebih banyak berisi keterangan tentang tata kerja organisasi dan adat istana seperti cara bersikap, berpakaian, dan penjelasan tentang lambang dan status sosial.

Hikayat Banjar Resensi 1 bertujuan menegakkan silsilah kerajaan Banjar dari awal hingga Sultan Suriansyah. Bagi Resensi 1 puncak cerita berada pada islamisasi kerajaan di bawah Sultan Suriansyah oleh Demak, sementara bagi Tutur Candi, itu justru bagian akhir cerita. Hal ini menunjukkan bahwa Hikayat Banjar Resensi 1 dibuat di masa keraton Islam di Banjarmasin (keraton III) sementara Tutur Candi Resensi 2 diduga merupakan satu teks fungsional keraton Negara-Daha yang bersifat kehinduan, dan tetap dijaga dan digunakan dalam pementasan wayang Abdul Muluk yang bernuansa nonIslami.

\section{Novel Lambung Mangkurat}

Novel Lambung Mangkurat ditulis pada tahun 2016, ratusan tahun setelah hipogramnya, Hikayat Banjar dan Tutur Candi lahir dari lisan para pencerita. Dalam pengantarnya, secara gamblang, Randu Alamsyah menjelaskan keterkaitan novel ini dengan Hikayat Banjar. Lambung Mangkurat adalah salah satu tokoh sentral di masa-masa awal berdirinya Nagara-Dipa, cikal bakal kerajaan Banjar (Alamsyah). Dalam Hikayat Banjar dan Tutur Candi, tokoh ini hadir dari episode 1 di masa Ampu Jatmika hingga episode 9 di masa Raden Sekar Sungsang (Maharaja Sari Kaburungan).

Novel ini sendiri memiliki jalan cerita yang berbeda dari Hikayat Banjar dan Tutur Candi. Cerita diawali kondisi yang cukup kacau pasca menghilangnya Ampu Mandastana. Salah satu bawahan utama Ampu Mandastana, Arya Megasari bermaksud naik tahta menggantikan Ampu mandastana. Di lain pihak, Lambung Mangkurat selaku putra Ampu Jatmika juga merasa berhak atas tahta. Dalam usahanya untuk meraih tahta itu, Lambung Mangkurat bertemu dengan Mayang, seorang perempuan jelita yang merupakan anggota komplotan pemberontak dari sisa-sisa kerajaan Tanjungpura yang pernah berkuasa di Banua Hujung Tanah dan bermaksud merebut kembali kekuasaan itu dari tangan Nagara Dipa.

Melalui perantaraan Mayang, Lambung Mangkurat bertemu Patih Singabarung, 
seorang patih dari kerajaan Kuripan. Kerajaan yang redup kiprahnya setelah Nagara Dipa berkembang pesat. Lambung Mangkurat bersepakat dengan Patih Singabarung untuk menyingkirkan Arya Megasari dalam sebuah serangan mendadak. Dalam serangan itu Arya Megasari berhasil dibunuh, tetapi alih-alih menyerahkan Nagara Dipa ke tangan Patih Singabarung, Lambung Mangkurat justru bekerja sama dengan komplotan Nusadipura pimpinan Mayang untuk membunuh Patih Singabarung dan menyingkirkan pasukannya.

Lambung Mangkurat mengharapkan penasbihannya sebagai raja, tetapi masa itu tak kunjung datang. Menjelang penobatan Lambung Mangkurat, Gajah Mada datang ke Nagara Dipa. Saat pulang, Gajah Mada meninggalkan sejumlah pasukan yang diperbantukan untuk melawan sisa-sisa tentara Kuripan. Lambung Mangkurat yang khawatir akan sepak terjang pasukan Majapahit itu justru menyiapkan sebuah taktik untuk menghancurkan sisa-sisa tentara Kuripan sekaligus membunuh seluruh pasukan bantuan Gajah Mada.

Setelah peristiwa berdarah itu mereda, Lambung Mangkurat masih merencanakan penasbihannya sebagai raja, tetapi ia justru menemukan batu sandungan, yaitu keponakannya, Patmaraga, yang semakin naik pamor dan tampak mengincar tahta. Pada satu titik, usaha pemberontakan dilakukan Patmaraga dan kelompok pendukungnya melawan Lambung Mangkurat, tetapi usaha itu kandas dan vonis mati dijatuhkan pada Patmaraga dan kelompoknya. Setelah perenungan yang cukup lama, akhirnya Lambung Mangkurat urung menghukum mati Patmaraga tetapi mengasingkannya. Dalam pengasingan, seseorang membunuh Patmaraga, Lambung Mangkurat mengira itu Mayang dan komplotannya. Tetapi saaat dikonfrontasi, Mayang menolak tuduhan itu. Yang mengejutkan dari semuanya adalah tiba-tiba saja Lambung Mangkurat meminta Mayang menjadi ratu di Nagara Dipa.
Lambung Mangkurat mencintai Mayang yang sekarang bernama Putri Junjung Buih. Sehingga ketika Putri Junjung Buih dekat dengan Sukmaraga, keponakan Lambung Mangkurat yang lain, hal itu melukainya. Bertepatan dengan itu, Gajah Mada kembali bermaksud mengambil alih sebagian wilayah Nagara Dipa. Mengantisipasi itu, Lambung Mangkurat memunculkan ide untuk mengawinkan Putri Junjung Buih dengan Pangeran dari Majapahit agar Nagara Dipa tetap aman. Hal itu memicu Sukmaraga untuk membunuh dirinya sendiri karena tidak terima kekasih hatinya menikah dengan orang lain.

Orang tua Sukmaraga sekaligus kakak Lambung Mangkurat, Ampu Mandastana dan istrinya yang terlampau sedih kehilangan kedua anaknya pun menyusul membunuh dirinya. Gajah Mada yang terseret suramnya suasana pasca bunuh diri tiga anggota keluarga kerajaan itu akhirnya surut keinginannya menguasai Nagara Dipa dan memutuskan pulang. Di akhir cerita, Lambung Mangkurat digambarkan benar-benar sendiri. Putri Junjung Buih menolaknya ikut serta dalam perjalanan ke negeri Champa sementara urusan negeri diserahkan pada Jampang Sasak, salah satu menterinya.

\section{Intertekstual Novel Lambung Mangkurat terhadap Hikayat Banjar dan Tutur Candi}

Sebagai teks yang menjadikan Hikayat Banjar dan Tutur Candi sebagai hipogramnya, intertekstual yang dialami novel Lambung Mangkurat pada Hikayat Banjar dan Tutur Candi dikategorikan sebagai intertekstual obligatori (obligatory intertextuality) karena pemahaman atas tokoh-tokoh, alur, dan latar pada novel tidak akan memadai tanpa mengetahui dan memahami Hikayat Banjar atau Tutur Candi sebagai hipogramnya. Pemahaman terhadap hipogram kelak juga sangat menentukan proses menemukan bentuk dekonstruksi yang dilakukan novel Lambung Mangkurat terhadap Hikayat Banjar dan Tutur Candi. Jika kita tidak membaca Hikayat Banjar dan Tutur Candi, kita tidak akan tahu bahwa novel tersebut mendekonstruksi tokoh 
serta jalan cerita Hikayat Banjar dan Tutur Candi. Tanpa memahami dengan baik Hikayat Banjar dan Tutur Candi, kita akan sulit mengetahui posisi tokoh-tokoh seperti Lambung Mangkurat, Ampu Jatmika, dan Putri Junjung Buih dalam kultur urang Banjar.

Keterjalinan mendalam antara novel Lambung Mangkurat dengan dua hipogramnya terdapat dalam jalan cerita dan tokoh-tokohnya. Dua unsur intrinsik ini adalah penanda paling subtantif yang membuat ketiga teks ini saling terhubung.

\section{Intertekstualitas Jalan Cerita}

Keterkaitan jalan cerita antara novel Lambung Mangkurat dengan Hikayat Banjar dan Tutur Candi hanya meliputi satu bagian saja dari banyak bagian-bagian dalam kedua hipogram itu. Cerita pada novel Lambung Mangkurat hanya berpusat pada masa-masa awal pembentukan Kerajaan Banjar yaitu ketika Ampu Jatmika menemukan Banua Hujung Tanah lalu mendirikan kerajaan Negara Dipa sampai masa pemerintahan Putri Junjung Buih. Ini periode yang sangat singkat dari bentangan periode Hikayat Banjar dan Tutur Candi yang panjang.

Terdapat sejumlah perbedaan dalam jalan cerita antara novel Lambung Mangkurat dan dua hipogramnya. Novel Lambung Mangkurat tampak jelas cenderung mengikuti alur cerita yang dibuat versi Hikayat Banjar daripada Tutur Candi. Diawali dengan narasi singkat keberangkatan kapal Ampu Jatmika menuju Banua Hujung Tanah, dan mengabaikan awal cerita Hikayat Banjar sendiri yang dimulai dari masa pemerintahan Saudagar Mangkubumi, ayah Ampu Jatmika, di wilayah Keling (Kediri). Dan sama sekali mengabaikan versi yang lebih berbelit-belit dari Tutur Candi yang memulai cerita bahkan sejak tetua negeri Keling yang mistis, Nabi Khidir.

Jika Hikayat Banjar dan apalagi, Tutur Candi menjelaskan dengan rinci proses pengkondisian dan pembangunan Banua Hujung Tanah yang ditemukan oleh Ampu
Jatmika hingga menjelma menjadi sebuah kerajaan, maka novel Lambung Mangkurat melewati bagian itu dan langsung masuk pada cerita di mana Arya Megasari bermaksud mengambil alih tahta sepeninggal Ampu Jatmika. Arya Megasari dalam Hikayat Banjar dan Tutur Candi memiliki versi nama lain yaitu Aria Magatsari, merupakan hulubalang keluarga Ampu Jatmika. Ia membantu Ampu Jatmika menundukkan wilayah Batang Tabalung, Batang Balangan, dan Batang Petak sekaligus memerintah di wilayah itu mewakili Ampu Jatmika. Dalam dua hipogramnya, Arya Megasari digambarkan sebagai bawahan raja yang setia, dan tidak memainkan intrik apapun untuk dapat berkuasa. Sangat berbeda dengan novel Lambung Mangkurat yang memosisikan Arya Megasari vis a vis dengan Lambung Mangkurat karena sama-sama menghendaki tahta.

Keinginan Lambung Mangkurat atas tahta Nagara Dipa juga merupakan hal lain yang membedakan novel Lambung Mangkurat ini dengan dua hipogramnya. Keinginan Lambung Mangkurat untuk berkuasa adalah pusat dari cerita dalam novel. Hal itulah yang menyebabkannya berkonflik dengan Arya Magatsari, Patmaraga, Patih Singabarung, dan Mayang (Putri Junjung Buih). Tetapi , dalam dua hipogramnya, Lambung Mangkurat justru tidak memiliki ambisi itu sama sekali. Dalam Hikayat Banjar disebutkan bahwa Lambung Mangkurat meyakini apa yang disampaikan ayahnya, Ampu Jatmika bahwa asal mereka bukan dari kalangan raja dan janganlah hendak menjadi raja karena akan membuat mereka binasa. Lambung Mangkurat dan kakaknya, Ampu Mandastana justru diminta ayahnya bertapa untuk menemukan (secara gaib) penguasa baru untuk Nagara Dipa.

Lambung Mangkurat mengamini dengan tegas sabda itu, sehingga ketika ayahnya wafat, ia dan Ampu Mandastana meminta kerajaan dikelola oleh Aria Magatsari dan Tumanggung Tatah Jiwa. Mari kita cermati kutipan berikut,

Kata Ampu Mandastana dan Lambu Mangkurat: "Hai Aria Magatsari dan 
Tumanggung Tatah Jiwa dan segala menteri, adapun segala astilah tahta perintah kerajaan itu jangan lagi berubah seperti astilah tahta ayahku dahulu itu. Maka segala perintah di dalam negeri ini kuserahkan jahatbaiknya pada Aria Magatsari dengan Tumanggung Tatah Jiwa." Maka sekaliannya mereka itu sembahnya menjunjung sabda: "Tuanku, hamba tiada anggan." Kata Аmpu Mandastana dan Lambu Mangkurat: "Aku jangan lagi diganang-ganang, kerana aku mengerjakan seperti pesan ayahku itu." Sudah demikian orang sekalian masing-masing pulang ke rumahnya, (Rass).

Terjemah: Kata Ampu Mandastana dan Lambu Mangkurat: "Hai Aria Magatsari dan Tumanggung Tatah Jiwa dan segala menteri, adapun segala urusan tahta perintah kerajaan itu jangan lagi berubah seperti urusan di masa tahta ayahku dahulu itu. Maka segala perintah di dalam negeri ini kuserahkan jahat-baiknya pada Aria Magatsari dan Tumanggung Tatah Jiwa." Maka mereka semua menyahut: "Tuanku, hamba tiada enggan." Kata Ampu Mandastana dan Lambu Mangkurat: "Aku jangan lagi dikenang, karena aku mengerjakan pesan ayahku itu." Setelahnya orangorang pulang ke rumahnya, (Rass).

Sementara itu dalam Tutur Candi, Lambu Jayawanagiri (Ampu Mandastana) dan Lambu (Lambung) Mangkurat secara otomatis menjadi raja menggantikan ayahnya mereka yang mangkat. Meski demikian, mereka justru berlomba-lomba mencari raja baru ketika suatu hari mereka mendengar suara gaib memerintahkan mereka membuang berhala sesembahan dan mencari raja baru.

Maka haripun sianglah maka baginda kedua itu dengan segera menyuruh himpunkan segala menteri punggawa habis terhimpun semuanya, maka baginda berdua bertitah kepada Patih Lawu dan Patih Dulu menyuruh himpunkan sekalian isinya negeri Candi Agung dan Kuripan, karena aku ada mendengar suara, jangan lagi kita menyembah berhala sebab meadakan putus cerita turun temurun raja, maka baiklah kita mencari raja sama manusia, maka Patih Lawu pun segera menghimpunkan seperti perintah itu, (Saleh:70).

Dalam dua hipogram, jelas tidak muncul konflik perebutan kekuasaan. Konflik hanya dimunculkan di dalam novel.

Di dalam novel juga diceritakan, keinginan Lambung Mangkurat untuk merebut tahta dari Arya Megasari menuntunnya untuk bekerja sama dengan kerajaan Kuripan di bawah pimpinan Patih Singabarung. Kerajaan Kuripan di dalam novel digambarkan sebagai kerajaan kecil yang menjadi terpinggirkan setelah Nagara Dipa menjadi kerajaan besar. Rajanya dikalahkan dan rakyatnya menepi ke daerah pinggiran. Ada dendam yang lama dipendam rakyat Kuripan terhadap Nagara Dipa. Pada hipogramnya, hal ini tak pernah terjadi. Bagi rakyat Kuripan, berintegrasi di bawah pemerintahan Nagara Dipa adalah sebuah kebahagiaan.

Perbedaan lainnya yang terasa mencolok antara novel Lambung Mangkurat dengan dua hipogramnya adalah ketiadaan hal-hal magis. Dalam Hikayat Banjar dan terlebih, Tutur Candi, hal-hal magis dan ajaib adalah bagian tak terpisahkan dari cerita. Setiap bagian cerita memiliki hal-hal magisnya. Puncak kemagisan cerita dalam Hikayat Banjar dan Tutur Candi adalah proses pemunculan Putri Junjung Buih. Putri Junjung Buih diceritakan muncul dari gumpalan buih putih besar di atas sungai, dan tidak mau keluar kecuali hari itu juga dibuatkan untuknya sebuah istana bertiangkan bambu berbintik dari gunung batu Piring, dan juga dibuatkan kain tenun yang dibuat dayangdayang istana. Dalam novel, keajaiban pemunculan Putri Junjung Buih sama sekali tidak tampak. Mayang sebagai ketua 
komplotan Nusadipura menghadang Lambung Mangkurat di atas sebuah kapal, dan ketika ia meniti titian turun dari kapal, ombak di sekitar kapal menerpanya. Imaji ini oleh Lambung Mangkurat membuatnya menjuluki Mayang sebagai Putri Junjung Buih.

Hal lain yang sama sekali tidak muncul di Hikayat Banjar dan Tutur Candi adalah cerita tentang kedatangan Gajah Mada ke Nagara Dipa. Dalam novel, kedatangan Gajah Mada dan armada lautnya merupakan bagian plot utama, tanpa kedatangan Gajah Mada, cerita akan sulit bergulir karena dengan kedatangan kali pertama Gajah Mada yang kemudian pulang lalu meninggalkan pasukan untuk membantu, Lambung Mangkurat terpikir untuk segera menyerang Kuripan dan menghancurkan sisa pasukan mereka, dan karena kedatangan kali kedua Gaja Mada yang ingin menganeksasi Nagara Dipa, Lambung Mengkurat berinisiatif mengawinkan Putri Junjung Buih dengan pangeran dari Majapahit. Hal yang kemudian memicu peristiwa bunuh diri Sukmaraga. Memasukkan tokoh Gajah Mada yang memiliki cerita dan dunianya sendiri merupakan suatu anomali. Masuknya Gajah Mada ke dalam cerita ini merupakan sesuatu yang out of imagination dalam kognisi sosial urang Banjar. Meski demikian, hal ini menunjukkan adalah bahwa daripada menunjukkan kuatnya pengaruh Majapahit (baca: jawa) secara tersirat seperti dalam dua hipogramnya, novel Lambung Mangkurat justru lebih vulgar menyatakan bahwa pengaruh itu demikian nyata, hadir dalam rupa seorang Gajah Mada.

Hal terakhir yang juga merupakan perbedaan substantif dari novel Lambung Mangkurat terhadap dua hipogramnya adalah penolakan jalan cerita pada novel untuk benarbenar mengawinkan Putri Junjung Buih dengan pangeran putra raja Majapahit. Dalam Hikayat Banjar dan Tutur Candi, Lambung Mangkurat mendatangi raja Majapahit untuk meminta putra yang dimiliki raja yang didapatkannya dari prosesi pertapaan. Dialah Raden Putra yang kelak bergelar Maharaja Suryanata. Mereka akhirnya menikah dan menurunkan putra putri penerus Nagara Dipa. Berbeda dengan novel Lambung Mangkurat di mana akhirnya Putri Junjung Buih urung menikah lalu melakukan perjalanan ke negeri Champa.

\section{Intertekstualitas Tokoh}

Dalam novel Lambung Mangkurat, tokohtokoh utamanya memiliki karakter yang jauh berbeda dari dua hipogramnya.

\section{(1) Lambung Mangkurat}

Secara fisik Lambung Mangkurat di dalam novel awalnya digambarkan sebagai lelaki yang penuh kekurangan. Hal itu dapat dilihat dari petikan berikut,

... Dia bertubuh gempal, cenderung gendut. Wajahnya kemerahan seperti mereka yang biasa banyak menghabiskan waktu menenggak arak. Kepalanya besar dengan dahi lebar memperlihatkan batas rambutnya yang menipis dengan cepat. Dia tak menyanggul rambut belakangnya yang panjang, yang sedikit menutupi anting yang sedang tren masa itu. Matanya dalam dengan cekungan yang kelak kuketahui dari cara hidupnya yang sangat jarang menikmati tidur panjang di malam hari karena jika tak larut dalam bukubukunya, dia mabuk dalam arakaraknya, (Alamsyah:29).

Kekurangan fisik di sana sini ini, kemudian berubah saat Lambung Mangkurat mulai berlatih fisik dalam persiapan untuk mewujudkan keinginan kuatnya merebut tahta. Tubuhnya mulai berotot dan lentur, menjelma menjadi bayangan ideal tentang Lambung Mangkurat yang dibayangkan pembaca saat membaca Hikayat Banjar dan Tutur Candi.

Lambung Mangkurat juga digambarkan sebagai orang yang ambisius, sangat berhasrat akan tahta. Sejak awal novel, ia diceritakan ingin menjadi raja di Nagara Dipa, dan berusaha mewujudkan itu dengan menyingkirkan 
Patih Arya Megasari. Lambung Mangkurat juga seorang politisi sejati. Pengarang menggambarkannya sebagai kadal yang pernuh warna: kerap berubah-ubah, acap kali licik tak berperikemanusiaan, disiplin, keras, manipulatif, (Alamsyah, 2018: 224). Ia memasang jebakan untuk membunuh Arya Megasari sekaligus menyingkirkan Patih Singabarung. Ia juga berhasil membunuh seluruh pasukan Majapahit yang ditinggalkan Gajah Mada di Nagara Dipa tanpa diketahui Gajah Mada. Ia juga berhasil menyingkirkan Patmaraga yang juga mengincar tahta, dan menggunakan taktik ingin mengawinkan Putri Junjung Buih dengan pangeran dari Majapahit agar sang putri tak lagi bersama Sukmaraga.

Tetapi , ia juga penuh dengan kelemahan. Lemah saat jatuh cinta. Ia jatuh cinta pada Mayang yang kelak menjadi Putri Junjung Buih. Ia bahkan rela melepas ambisinya menjadi raja dan menyerahkan kekuasaan itu pada Mayang karena sejak awal memang hal itu yang diinginkan Mayang atas Nagara Dipa. Ia juga begitu penuh penyesalan dengan tindakan bunuh diri Sukmaraga, kakaknya, Ampu Mandastana, dan iparnya. Ia juga menyesali terbunuhnya Patmaraga di pengasingan setelah sebelumnya urung membunuh Patmaraga yang melakukan makar. Pengarang menggambarkannya sebagai lelaki yang kesepian dan memahami bahwa jalan sepi itu memang merupakan takdirnya.

Sementara itu, dalam Hikayat Banjar, Lambung Mangkurat digambarkan sebagai anak raja yang tidak memiliki ketertarikan terhadap istana dan tahta ayahnya. Ia dan saudaranya, Ampu Mandastana hanya bermain, berburu, mencari ikan, atau memainkan barang-barang lain kesukaannya (Rass:235). Ia mematuhi wasiat ayahnya untuk mencari raja baru, dan ketika Putri Junjung Buih berkuasa ia mengabdikan dirinya untuk menjadi pembantu raja yang setia. Tak sekalipun digambarkan kondisi emosional Lambung Mangkurat, kecuali bahwa ia sangat berkhidmat untuk penguasa Nagara Dipa. Lambung Mangkurat memang diceritakan membunuh kedua keponakannya, tetapi semata agar ia tak harus mengabdi sebagai bawahan pada dua keponakannya. Tak lebih dari itu.

Di Tutur Candi, Lambung Mangkurat diangkat menjadi raja bersama saudaranya, Lambu Jayawanagiri (Ampu Mandastana) menggantikan ayahnya dan kelak menyerahkan tahta itu sukarela kepada Pustri Junjung Buih setelah sebuah suara mengingatkannya. Lambung Mangkurat digambarkan sebagai raja yang terlalu adil, dan masyhur, sabar, dan murah hati pada rakyatnya, (Saleh:53).

\section{(2) Putri junjung Buih}

Pembaca tidak mengenal Putri Junjung Buih dalam novel Lambung Mengkurat sebelum bab dua puluh satu. Sebelumnya dia bernama Mayang. Sebagai Mayang, putri Junjung Buih jauh dari apa yang digambarkan Hikayat Banjar dan Tutur Candi. Di Hikayat Banjar dan Tutur Candi, putri Junjung Buih benar-benar menunjukkan keagungannya. Ia putri yang muncul dengan cara mistis, memberikan permintaan-permintaan mistis, lalu tiba-tiba memimpin Nagara Dipa. Ia menolak ketika diminta bersuami karena menaruh hati pada Patmaraga sekaligus Sukmaraga, tetapi akhirnya bersedia dengan syarat suaminya berasal dari anak hasil pertapaan juga seperti dirinya. Mari kita lihat kutipan berikut,

... "Baiklah Tuan Puteri bersuami jua, boleh didengar orang sudah bersuami." Maka sahut tuan puteri, "Maulah hamba bersuami kalau anak orang baoleh bertapa jua." Maka sahut Lambu Mangkurat, "Terlalu amat susah karena tiada ada orang mendengar orang yang baoleh anak oleh bertapa," maka sahut tuan puteri, "Hai Bapakku, adalah ia," maka kata Lambu Mangkurat, "Dimanakah adanya?" Maka katanya tuan puteri, "Karena yang beranak itu raja Majapahit baoleh ia bertapa maka itulah aku mau." Maka kata ratu 
Kuripan (Lambu Mangkurat -pen), "Baiklah," (Saleh:79)

Dari kutipan tersebut, tampak watak ningrat Puteri Junjung Buih yang tidak mau menikah kecuali dengan calon suami yang sama mistisnya dengan dirinya. Puteri Junjung Buih dalam dua hipogram, Hikayat Banjar dan Tutur Candi menjadi representasi kaum elit negeri yang tampil dengan segala kebesaran dan keagungannya. Berbeda sekali dengan Mayang, yang merupakan pemimpin komplotan Nusadipura. Komplotan ini adalah para pemberontak garis keras yang menuntut haknya atas kepemimpinan. Mayang digambarkan politis, keras dan penuh intrik untuk bisa mencapai tujuannya. Ia sama manipulatif dan liciknya dengan Lambung Mangkurat. Ia membunuh Patih Singabarung untuk menciptakan satu kondisi mental di mana Lambung Mangkurat akan merasa berhutang padanya. Dan ketika berkuasa, pada akhirnya, ia tak segan-segan mengabaikan Lambung Mangkurat yang telah dengan rela mengantarkannya menjadi penguasa Nagara Dipa.

Setelah mengetahui intertekstualitas novel Lambung Mangkurat terhadap dua hipogramnya, tampak sejumlah perbedaan dari halhal yang sejalan antara ketiga teks, muncullah pertanyaan, mengapa perbedaan-perbedaan itu terjadi? Mengapa pengarang novel tidak membiarkan saja ceritanya selaras dengan dua hipogramnya, mengapa sebagian justru mendistorsi -jika tidak bisa dikatakan merusak- cerita yang sudah mapan selama ratusan tahun?

Dalam hal ini dapat dikatakan bahwa novel Lambung Mangkurat telah mendekonstruksi dua hipogramnya. Dekonstruksi dalam hal ini mengacu pada usaha untuk membaca lalu menuliskan kembali cerita tentang Hikayat Banjar/ Tutur Candi dan mengeluarkannya dari kondisi mapan yang selama ratusan tahun ini melingkupinya. Novel Lambung Mangkurat mencoba mereproduksi interpretasi cerita Hikayat Banjar/ Tutur Candi yang sakral dalam dimensi yang lebih profan tetapi justru lebih manusiawi.

\section{Dekonstruksi Novel Lambung Mangkurat terhadap Hikayat Banjar dan Tutur Candi}

Ketika pada bab satu novel langsung masuk pada suasana yang kurang kondusif di tengah masayarakat akibat suasana keraton yang diliputi tajamnya aroma perebutan tahta, maka ini menjadi usaha pertama pengarang untuk mendekonstruksi cerita Hikayat Banjar/ Tutur Candi. Pengarang ingin menyampaikan bahwa perebutan dan kehausan personal yang terlibat untuk bisa berkuasa adalah bagian tak terpisahkan dari sebuah mekanisme kekuasaan. Setua umur peradaban manusia, prosesi jalannya kekuasaan tak pernah benar-benar berjalan langgeng. Pertarungan untuk memperebutkannya akan selalu ada sebagai perwujudan watak dasar manusia.

Pengarang menolak kondisi ideal dan lurus yang ditawarkan dua hipogramnya dalam proses penciptaan dan pembangunan kerajaan Nagara Dipa di mana Ampu Jatmika datang dengan kemegahannya, menaklukkan semua wilayah di Banua Hujung Tanah tanpa perlawanan sedikitpun, bahkan kerajaan Kuripan yang sudah lebih dahulu ada, rajanya dengan sukarela menyerahkan wilayah kerajaan dan berintegrasi ke dalam Nagara Dipa. Setelah Ampu Jatmika mangkat, anak-anaknya bertapa mencari raja baru. Pengarang novel Lambung Mangkurat seolah menyatakan, tak ada hal semacam itu. Pengarang lalu menawarkan cerita yang lebih masuk akal dan sesuai dengan logika zaman, bahwa perebutan tahta terjadi setelah ketiadaan Ampu Jatmika dengan dua simbol golongan yang biasanya sangat berkepentingan untuk memegang tampuk kekuasaan, royal family dan military force. Pengarang juga menyuguhkan cerita bahwa dalam usaha menegakkan kekuasaan di banua Hujung Tanah, Nagara Dipa jelas mendapatkan resistensi dari penguasa yang mereka taklukkan, yaitu kerajaan Kuripan, dan komplotan Nusadipura yang merupakan jejak kekuasaan yang jauh lebih tua, kerajaan Tanjungpura.

Hasrat berkuasa yang menjadi ruh cerita dalam novel Ini adalah sebuah respon 
pembacaan ulang, bahwa sedianya politik dan kekuasaan bukan perkara sederhana hitam putih yang mereduksi ambisi dan keserakahan seperti Lambung Mangkurat versi Hikayat Banjar dan Tutur candi yang ketika diminta orang tuanya agar jangan berkuasa, maka surutlah keinginannya untuk berkuasa. Bukan pula dunia di mana seorang bawahan tidak memiliki hasrat untuk naik ke puncak kekuasaan seperti Aria Magatsari. Dalam novel Lambung Mangkurat, politik adalah seni (untuk) berkuasa, bukan hanya amanah yang harus diemban selurus-lurusnya.

Novel Lambung Mangkurat juga coba membaca dan menuliskan ulang mengenai rimbunnya hal-hal gaib dalam dua hipogramnya, menjadi nihil sama sekali. Tokoh dan peristiwa dalam novel diturunkan derajatnya dari magis, fantastis dan ajaib menjadi tokoh dan peristiwa yang masuk dalam akal manusia. Hal-hal yang awalnya magis, dirasionalisasi oleh pengarang novel, termasuk bagian paling masyhur dari Hikayat Banjar/Tutur candi yaitu keluarnya Putri Junjung Buih secara mistis dari buih sebagai manifestasi tapa Lambung Mangkurat mencari raja baru untuk Nagara Dipa. Bagian itu dibuat sedemikian rupa hingga masuk akal.

Penurunan derajat pada level kemanusiaan ini juga dilakukan pengarang pada tokohtokoh utamanya, Lambung Mangkurat dan Putri Junjung Buih. Penggambaran fisik Lambung Mangkurat dan Putri Junjung Buih yang awalnya kurang ideal dan sifatnya yang jauh dari kesempurnaan merupakan bentuk dekonstruksi novel ini atas dua hipogramnya. Pengarang ingin membawa cerita yang begitu sakral dalam tradisi tutur masyarakat Banjar ke dalam dimensi yang lebih bisa diterima zaman. Sebagian manusia Indonesia hari ini telah dimasuki kesakralan baru berwujud kecenderungan mewaspadai kebenaran karena sudah sering terperdaya oleh berbagai bentuk kebenaran, akan sulit menerima cerita-cerita yang sejak awal sudah terasa kemuskilannya. Orang-orang semacam ini cocok membaca novel Lambung Mangkurat, yang akan melihat peristiwa demi peristiwa dalam novel bukan sebagai cerita fantastis yang rentan menimbulkan keragu-raguan, tetapi cenderung melihat itu sebagai drama politik biasa. Tetapi di sisi lain, masih banyak juga masyarakat yang hidup dalam alam romantisme kesakralan lama ini. Mereka akan membaca dan menerima Hikayat Banjar/ Tutur Candi lengkap dengan semua keajaiban dan kemuskilannya. Kelompok ini tidak cocok, dan justru berpeluang merisistensi novel Lambung Mangkurat.

Novel ini juga telah merefleksikan pandangan non-jawa yang menolak untuk tunduk terhadap jawa sebagai penguasa. Berbeda dari hipogramnya (terutama Hikayat Banjar) yang cenderung menasbihkan diri sebagai subordinat jawa di mana mereka berpakaian dan beradat-istiadat seperti orang-orang Majapahit, novel Lambung Mangkurat terang-terangan menunjukkan usaha jawa untuk mengokupasi Nagara Dipa. Alih-alih membiarkannya, Lambung Mangkurat justru membunuhi pasukan yang ditinggalkan untuk membantunya, dan di akhir cerita, putri Junjung Buih tak menikah dengan pangeran Majapatih manapun.

Pada akhirnya kita akan melihat bahwa pengarang novel merombak hampir keseluruhan cerita ini, hanya menyisakan nama tokoh, dan plot utama: Lambung Mangkurat menemukan raja untuk Nagara Dipa dan menjadi patih di bawah raja, membunuh keponakannya, dan mencoba mencarikan jodoh untuk putri, yaitu pangeran Majapatih. Tetapi karakter tokoh, dan jalan cerita telah didekonstruksi sebagai bentuk pemaknaan ulang terhadap dua hipogramnya.

\section{PENUTUP}

Dari paparan di atas dapat disimpulkan bahwa novel Lambung Mangkurat karya Randu Alamsyah memiliki relevansi dengan dua teks lainnya yaitu Hikayat Banjar dan Tutur Candi. Novel Lambung Mangkurat adalah hipogram atau teks yang dipengaruhi oleh kedua teks tersebut. Intertekstualitas novel Lambung Mangkurat pada Hikayat 
Banjar dan Tutur Candi dikategorikan sebagai intertekstual obligatori (obligatory intertextuality) karena pemahaman atas tokoh-tokoh, alur, dan latar pada novel tidak akan memadai tanpa mengetahui dan memahami Hikayat Banjar atau Tutur Candi sebagai hipogramnya.

Terkait Hikayat Banjar dan Tutur Candi, novel Lambung Mangkurat melakukan dekonstruksi atas kedua teks tersebut. Dekonstruksi dilakukan dengan jalan mengubah jalan cerita, mengubah karakter tokoh, dan meniadakan hal-hal gaib dan ajaib yang sebelumnya sangat terasa dalam Hikayat Banjar dan Titur Candi.

Selanjutnya, diharapkan penelitian interteksual dekonstruktif ini dapat terus berkembang sebagai model penelitian teks postruktural, sehingga pembaca tidak hanya melihat satu teks berhubungan dengan teks lain, tapi bisa melihat bagaimana hubungan tersebut berjalan termasuk perubahanperubahan apa yang mungkin terjadi pada teks kemudian atas teks sebelumnya.

\section{DAFTAR PUSTAKA}

Alamsyah, R. Lambung Mangkurat. Laksana, 2018.

Allen, G. Intertextuality. Routledge, 2000.

Asmarani, RE. "Dekonstruksi Budaya Kekuasaan Dalam Ca Bau Kan Karya Remy Silado." Sabda: Jurnal Kajian Kebudayaan, vol. 10, 2017, pp. 1-10.

Elmo Raj, P. P. “Text/Texts: Interrogativy Julia Kristeva's Concept of Intertextuality.” Research Journal of Humanities and Social Science, vol. 3, no., 2015, pp. 77-80.

Fitzsimmons, J. "Romantic and Contemporary Poetry Reading." Retrieved from CQ University ECourse, 2013, http://moodle.eqo.edu.au.

Ghofur, A. "Analisis Dekonstruksi Tokoh Takeshi Dan Mitsusaburo Dalam Novel Silent Cry Karya Kenzaburo Oe Perspektif Jacques Derrida.” Jurnal Oktara, 1, vol. 1, 2014, pp. 57-76.

Jacobmeyer, H. "Ever After: A Study in Intertextuality." Retrieved from Carl Hanser Verlag, 1998, http://webdoc.sub.gegd.de/edoc/ia/eese/artic98/jacobm/88_89.html.

Norris, C. Deconstruction, Theory and Practice. Routledge, 2004.

Nurgiyantoro, Burhan. Teori Pengkajian Fiksi. Gadjah Mada University Press, 2015.

Purwanti. "Dekonstruksi Struktural Penceritaan Dalam Novel Arok-Dedes: Kajian Intertekstual." Jurnal Avatisme, vol. 20, 2017, pp. 190-210.

Rass, J. J. Hikayat Banjar (Trans). Edited by Siti Hawa Saleh, Percetakan Dewan Bahasa dan Pustaka, 1968.

Rokhmansyah, A. Studi Dan Pengkajian Sastra: Perkenalan Awal Terhadap Ilmu Sastra. Graha Ilmu, 2014.

Saleh, M. I. Tutur Candi. Balai Pustaka \& Perpustakaan Nasional, 1986.

Suciati, E. "Dekonstruksi Patriarki Khaled Hossaeni Dalam Novel 'A Thousand Splended Sun.'” Jurnal Diglossia, vol. 9, 2017, pp. 1-10.

Supriadi, S. Transformasi Nilai-Nilai Ajaran Islam Dalam “Ayat-Ayat Cinta” Karya Habiburrahman ElShirazy, Kajian Interteks. Universitas Diponegoro, 2006.

Yaumi, Sarach. "Kajian Intertekstual ‘Sang Pemimpi’ Karya Andrea Hirata Dan 'Mengejar-Ngejar Mimpi’ Karya Dedi Padiku.” Jurnal Tekstual, vol. 17, 2019, pp. 1-6. 